\title{
BMJ Open Effect of exercise on anthropometric measures and serum lipids in older individuals: a systematic review and meta-analysis
}

\author{
Carol L Kuhle, Mark W Steffen, Paul J Anderson, Mohammad Hassan Murad
}

To cite: Kuhle CL, Steffen MW, Anderson PJ, et al. Effect of exercise on anthropometric measures and serum lipids in older individuals: a systematic review and meta-analysis. BMJ Open 2014:4:e005283. doi:10.1136/bmjopen-2014005283

- Prepublication history and additional material is available. To view please visit the journal (http://dx.doi.org/ 10.1136/bmjopen-2014005283).

Received 20 March 2014 Revised 28 May 2014 Accepted 30 May 2014
CrossMark

Division of Preventive Medicine, Mayo Clinic, Rochester, Minnesota, USA

Correspondence to Dr Carol L Kuhle; kuhle.carol@mayo.edu

\section{ABSTRACT}

Objectives: Overweight and obesity are increasing in individuals over age 60 years. This systematic review quantifies the effect of exercise on body mass index (BMI), waist circumference (WC) and lipids in overweight and obese individuals over the age of 60 years.

Settings: Nine randomised controlled trials conducted in Brazil, Great Britain, Iceland, Japan and the USA compared aerobic and/or resistance exercise with a control group.

Participants: Final analysis reviewed 1166 participants over the age of 60 years for 3-9 months. Primary outcome measures: This study reviewed the effects of exercise on BMI, WC and low-density lipoprotein (LDL).

Results: Exercise produced a significant reduction in BMI $\left(-1.01 \mathrm{~kg} / \mathrm{m}^{2}, 95 \% \mathrm{Cl}-2.00\right.$ to -0.01$)$ and WC $(-3.09 \mathrm{~cm}, 95 \% \mathrm{Cl}-4.14$ to -2.04$)$ but not LDL cholesterol $(-0.31 \mathrm{mg} / \mathrm{dL}, 95 \% \mathrm{Cl}-0.81$ to $0.19)$. Analyses revealed substantial heterogeneity likely due to the type and intensity of exercise. Data on adverse effects were minimal. The overall level of evidence is moderate due to imprecision and heterogeneity.

Conclusions: Exercise in overweight and obese older individuals improves anthropometric measures such as BMI and WC. The effect of exercise on serum lipids is unclear.

\section{BACKGROUND}

Overweight (body mass index (BMI) $25-29.9 \mathrm{~kg} / \mathrm{m}^{2}$ ) and obesity $\left(\right.$ BMI $>30 \mathrm{~kg} / \mathrm{m}^{2}$ ) are associated with an increased risk of allcause mortality, cardiovascular disease, diabetes and cognitive disability. ${ }^{1}$ While BMI is a calculation based on height and weight, obesity can also be defined based on waist circumference (WC) or waist-hip ratio (WHR). Men with a WC $\geq 102 \mathrm{~cm}\left(40^{\prime \prime}\right)$ and women $\geq 88 \mathrm{~cm}$ or a WHR $>1$ in men or $>0.9$ in women defines abdominal or central obesity. Central obesity is an indicator of excess visceral

\section{Strengths and limitations of this study}

- Demonstrates the effectiveness of programmes designed to promote physical activity in older persons.

- Synthesises a large body of heterogeneous evidence about how exercise programmes may benefit obese and overweight individuals over 60 years old.

- Power may be limited by small numbers of participants relative to other large studies of health behaviours in older persons.

- Applicability and implementation may be limited due to varying characteristics of exercise programmes and regimens tested in the trials.

fat and is regarded as a more accurate measure of associated health risk. ${ }^{23}$

The prevalence of overweight and obesity has been increasing in people over the age of 60 years (from $60.1 \%$ and $22.2 \%$ in 1988 1994 to $68.6 \%$ and $30.5 \%$ in $2005-2006){ }^{4}$ Because ageing reduces daily energy requirements, the decreased physical activity also associated with normal ageing exacerbates the onset of central obesity and loss of lean muscle mass. ${ }^{5-7}$ The Behavioral Risk Factor Surveillance Survey (BRFSS) reported 28-34\% of adults aged $65-74$ and $35-44 \%$ over age 75 engage in no leisure time physical activity. ${ }^{8}$ Conversely, only $13 \%$ of individuals between ages 64 and 75 and only $6 \%$ over age 75 report vigorous physical activity. ${ }^{1}$

Several systematic reviews have assessed a variety of health issues related to obesity and ageing. Beydoun $e t a t^{9}$ reported an increased risk of cognitive disability associated with being overweight and obese elders. Latham et $a l^{10}$ found improvements in muscle strength and gait speed with progressive resistance strength training, but the effect on physical disability in older adults was unclear. Another review of observational and interventional studies found that intensive 
counselling promoted modest sustained weight loss with possible functional improvement. ${ }^{11}$ A clinical review by Gostic outlined the critical role of exercise and its impact on the loss of independence in later years of life. ${ }^{12}$

Uncertainty remains about the effect of progressive resistance strength training and/or aerobic exercise on weight reduction, changes in body composition and modulation of metabolic risk factors for cardiovascular disease. Inference from many of these observational studies is limited due to inherent methodological limitations such as selection bias and confounding. Therefore, we conducted this systematic review and meta-analysis to appraise and summarise the randomised controlled trial (RCT) evidence regarding the impact of exercise on body composition and serum lipids.

\section{METHODS}

\section{Inclusion criteria}

We included RCTs of older obese participants (mean age of 60 years or above with a BMI $>25 \mathrm{~kg} / \mathrm{m}^{2}$ or WC $>102 \mathrm{~cm}$ in men, $88 \mathrm{~cm}$ in women). We excluded studies enrolling individuals with diabetes mellitus, cognitive impairment, known cardiovascular disease or participants who were deficient in one or more activities of daily living. We also excluded studies with follow-up less than 3 months and those that involved pharmacological therapy.

Primary interventions included resistance and/or aerobic exercise programmes. Diet interventions were included if they were either the same for the intervention and control groups, or one of the comparison interventions. Resistance exercise was defined as strength training where participants exercised their muscles against an external force. Aerobic exercise was defined as a system of physical conditioning designed to improve circulatory or pulmonary function through exercise. The overall intensity of exercise could be measured by heart rate, heart rate reserve, oxygen consumption, rating of perceived exertion or metabolic equivalents. The outcomes of interest were anthropometric measures including BMI and WC, serum lipids as a surrogate for cardiovascular risk and adverse effects of exercise.

\section{Search strategy}

Controlled vocabulary and text words were used to search for the concepts of age, overweight and obese, elderly, exercise therapy, metabolic risk factors, sedentary, cardiovascular risk factors and health status indicators, with limits of human participants and RCTs. Databases searched included PubMed/MEDLINE, EMBASE, SCIRUS, Cochrane Database of Systematic Reviews, Cochrane Controlled Trials Register and clinicaltrials.gov. Two independent reviewers made decisions on the included articles. A third reviewer was available for any differences of opinion. The initial literature search was conducted on 11 January 2011 with query of articles from 1990 to 2010. An additional literature search was conducted on 15 January 2014 with a query of articles from 2011 to 2013. The detailed search strategy is in the online supplementary appendix. Data from the published reports were sufficient for analysis; hence, we did not contact the authors of the included studies.

\section{Study quality}

The methodological quality (risk of bias) was evaluated using the Cochrane Risk of Bias Tool that addresses the domains of randomisation adequacy, blinding, allocation concealment, whether the intention-to-treat analysis was utilised, and attrition rate. ${ }^{13}$

\section{Statistical analysis}

We estimated the weighted mean difference and $95 \%$ CIs from each study and pooled across studies using a random effects model. We chose this outcome measure because the outcomes of interest (BMI, WC, serum lipids) had natural units that were consistent across trials. The weighted mean difference preserves the natural units when estimates are pooled across studies. We chose the random effects model because we expected heterogeneity across study participants and settings. This model incorporates within-study and betweenstudy heterogeneity in the CIs. ${ }^{14}$ We used the I-squared statistic $\left(\mathrm{I}^{2}\right)$ to assess heterogeneity of the treatment effect across studies. ${ }^{15}$ We evaluated publication bias by visual inspection of funnel plots and assessment of their symmetry. We did not conduct statistical testing for funnel asymmetry because of the small number of studies, making analysis unreliable. ${ }^{16}$ We planned to conduct subgroup analysis evaluating aerobic versus resistance exercise and comparing different levels of exercise intensity. We planned to test any assumptions in sensitivity analysis. Analysis was conducted using Comprehensive Meta-analysis V.2, Biostat, Englewood, New Jersey, USA (2005).

\section{RESULTS}

\section{Study characteristics}

The results of the literature search and study selection process are described in figure 1 . We included nine RCTs that enrolled 1166 individuals. The length of the trials varied from 3 to 9 months in duration. The participants studied were all healthy, mostly white individuals living independently in the community. One trial exclusively enrolled women ${ }^{17}$ whereas the remaining trials enrolled both sexes. The mean ages ranged from $60 \pm 1.6$ to $80.8 \pm 4.7$ years. Exercise (EX) interventions included aerobic, resistance training (RT) or a combination of both compared with a sedentary control or a control that was sedentary with some calorie restriction (CR). One study compared EX with RT and one compared EX with EX combined with CR. Aerobic exercise was of moderate intensity based on $50-55 \%$ of maximum heart rate or high intensity (HI) based on $75-80 \%$ of heart 


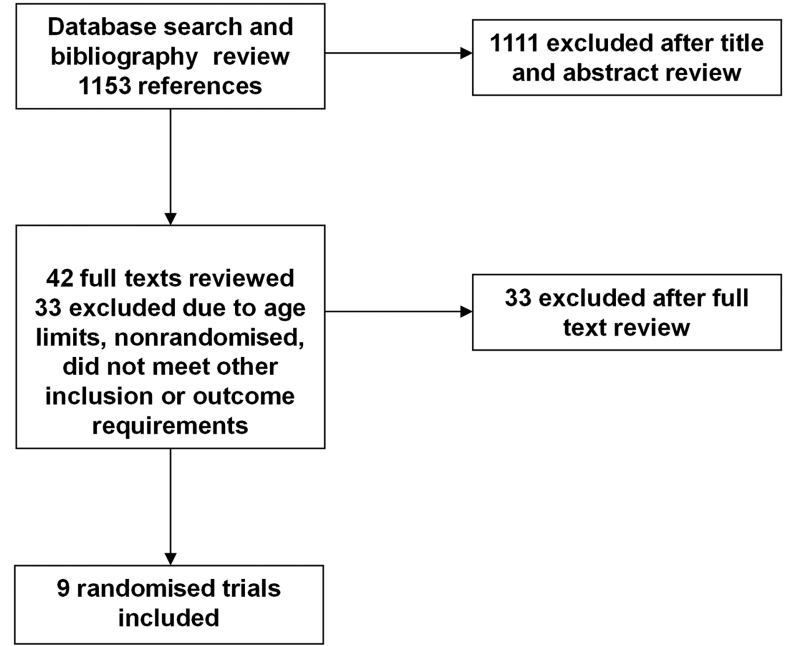

Figure 1 The process of study selection.

rate obtained from $\mathrm{VO}_{2}$ max at baseline. Resistance exercise was performed with a progressive increase of weight load against muscular resistance. CR was measured in $\mathrm{kcal} /$ day or by the goal of per cent reduction of body weight. Study characteristics are described in table 1.

\section{Risk of bias}

All the included trials reported adequate random allocation. Only two studies described how the allocation was made, and none of the studies discussed allocation concealment. ${ }^{18}{ }^{19}$ Only three of nine studies clearly performed intention-to-treat analysis, ${ }^{18-20}$ while two studies used the original number randomised without specifying it as an intention-to-treat analysis. ${ }^{17}{ }^{21}$ Only five studies explained reasons for withdrawal or dropout. ${ }^{8-20} 2223$ The number of participants in each group was balanced in all trials except one. ${ }^{18}$ None of the studies were blinded which would be difficult given the nature of the interventions. Adherence to the exercise protocols was reported in five studies. ${ }^{17-20}{ }^{23}$ Risk of bias indicators is summarised in table 2. The overall risk of bias for the outcomes of interest was moderate.

\section{Meta-analysis}

Exercise produced a significant reduction in BMI $\left(-1.01 \mathrm{~kg} / \mathrm{m}^{2}, 95 \%\right.$ CI -2.00 to -0.01$)$ and WC $(-3.09 \mathrm{~cm}, 95 \%$ CI -4.14 to -2.04 ; see figures 2 and 3$)$. Measures of heterogeneity (the $\mathrm{I}^{2}$ statistic) were high, exceeding $50 \%$. This can likely be explained by the type and intensity of exercise across trials as well as the differences in physical activity of the control groups. Results are depicted in figures 2 and 3.

\section{Serum lipids}

The effect of exercise on serum low-density lipoprotein (LDL) cholesterol in older persons was not statistically significant $(-0.31 \mathrm{mg} / \mathrm{dL}, \quad 95 \%$ CI -0.81 to 0.19$)$. Meta-analysis was associated with substantial heterogeneity $\left(\mathrm{I}^{2}>50 \%\right)$. Results are depicted in figure 4 . Data on triglycerides and high-density lipoprotein (HDL) cholesterol were insufficient for meta-analysis. In the studies that compared HI exercise with a control group $^{19} 202223$ only one study reported a significant increase in HDL in the intervention group $(3 \pm 3$ compared with $-0.3 \pm 0.7$; analysis of variance $\mathrm{p}=0.01) .{ }^{23}$ One study reported a significant decrease in triglycerides in the intervention group $(-0.45(-0.069$ to -0.020$)$ compared with $0.003(-0.020$ to 0.025$) \mathrm{mg} / \mathrm{dL}$; analysis of covariance $\mathrm{p}=0.006) .{ }^{19}$ When EX plus CR was compared with control in a study by Villareal et al, ${ }^{18}$ there was a significant decrease in triglycerides $(-45 \pm 63$ compared with $0 \pm 36$; analysis of variance $\mathrm{p}=<0.05$ ) but a nonsignificant decrease in HDL. According to Boardley et al, comparisons of EX, RT and a combination of EX and RT with control showed a decrease in triglycerides in all three interventions with the greatest decrease in the EX group compared with control $(-37.9 \pm 72$ compared with $-8.2 \pm 89$ ). There was also a small, but insignificant, decrease in HDL in all four groups. ${ }^{22}$

\section{Adverse events}

All studies reviewed had pre-enrolment screening and some level of physical examination and laboratory tests to exclude individuals at risk for adverse cardiovascular or orthopaedic outcomes during the trial. An exercise stress test was performed prior to enrolment in five trials. ${ }^{17} 182021{ }^{23}$ In four trials, all the exercise interventions were supervised. ${ }^{12} 17182123$ One study that compared aerobic exercise with control reported a participant with an exacerbation of osteoarthritis of the knees and another participant with exercise-induced palpitations. ${ }^{20}$ Otherwise, there were no adverse effects reported.

\section{Sensitivity and subgroup analyses}

Two RCTs had a three-arm design (HI exercise vs medium intensity exercise vs a control group). ${ }^{17}{ }^{21} \mathrm{In}$ order to not count the common control group twice and inflate the weight of these two studies, we only used one intervention group at a time. In sensitivity analysis, there was no change to study conclusions regardless of which intervention group is analysed. One RCT had a cross-over design. ${ }^{24}$ We repeated the analysis three times using the first phase; the second phase or both phases combined using various correlation coefficients. The conclusions of the main analysis (ie, statistically significant reduction in BMI and WC) did not change. Data were insufficient to conduct subgroup analysis comparing aerobic versus strength training or based on exercise intensity.

\section{DISCUSSION}

This systematic review summarised the available evidence focused on how exercise influences BMI, WC and LDL in older overweight and obese individuals. Exercise 
Table 1 Study characteristics

\begin{tabular}{|c|c|c|c|c|c|c|}
\hline Study year/origin & $\begin{array}{l}\text { Length } \\
\text { (months) }\end{array}$ & Sample size & Sex & Age & BMI $\left(\mathrm{kg} / \mathrm{m}^{2}\right)$ & Interventions \\
\hline \multirow[t]{2}{*}{ Stewart et $a P^{3} 2005 /$ USA } & 6 & EX 57 & $\begin{array}{l}\text { F } 31 \\
\text { M } 26\end{array}$ & $63 \pm 1.5$ & $29.4 \pm 1.1$ & $\begin{array}{l}3 \text { days/week: } \mathrm{RT}, 7 \mathrm{EX} 2 \text { sets of } 10-15 \text { reps } 45 \text { min; aerobic } \\
\text { at } 60-90 \% \mathrm{VO}_{2} \max \end{array}$ \\
\hline & & Ctrl 58 & $\begin{array}{l}\text { F } 31 \\
\text { M } 27\end{array}$ & $64 \pm 1.7$ & $29.7 \pm 1.4$ & NIA guidelines for EX and AHA Step I Diet given to both groups \\
\hline \multirow[t]{3}{*}{ Coker et a ${ }^{1}$ 2006/USA } & 3 & MI 7 & NR & $73 \pm 2$ & $29 \pm 1$ & $\begin{array}{l}\text { Cycle ergometer } 4-5 \text { days/week } \\
50 \% \mathrm{VO}_{2} \max \end{array}$ \\
\hline & & $\mathrm{HI} 7$ & & $73 \pm 2$ & $31 \pm 1$ & $\begin{array}{l}\text { Cycle ergometer } 4-5 \text { days/week } \\
75 \% \mathrm{VO}_{2} \max \end{array}$ \\
\hline & & Ctrl 7 & & $70 \pm 3$ & $31 \pm 1$ & Usual sedentary activity \\
\hline \multirow[t]{3}{*}{ DiPietro et al ${ }^{17} 2006 / U S A$} & 9 & MI 9 & All $F$ & $73 \pm 3$ & $28 \pm 4.5$ & Expend $300 \mathrm{kcal} /$ day at $80 \% \mathrm{VO}_{2} \max$ \\
\hline & & HI 9 & & $72 \pm 3$ & $26.3 \pm 3$ & Expend $300 \mathrm{kcal} /$ day at $65 \%$ peak $\mathrm{VO}_{2} \max$ \\
\hline & & Ctrl 7 & & $75 \pm 5$ & $27 \pm 4.7$ & Stretching and strengthening Thera-Bands and Thera-Balls \\
\hline \multirow[t]{2}{*}{ Villareal et $a \rho$ 2006/USA } & 6 & INT 17 & $\begin{array}{l}\text { F } 12 \\
\text { M } 4\end{array}$ & $69 \pm 5$ & $39 \pm 5$ & $\begin{array}{l}\text { Energy deficit of } 750 \mathrm{kcal} / \text { day, EX } 30 \mathrm{~min} \text { endurance } \\
\left(70 \% \mathrm{VO}_{2} \text { peak), } 30 \mathrm{~min} \text { of strength training, } 15 \mathrm{~min} \text { balance, }\right. \\
\text { EX } 3 \text { non-consecutive day/week in group }\end{array}$ \\
\hline & & Ctrl 10 & $\begin{array}{l}\mathrm{F} 6 \\
\mathrm{M} 4\end{array}$ & $71 \pm 4$ & $39 \pm 5$ & Usual sedentary PA \\
\hline \multirow[t]{4}{*}{ Boardley et $a^{22} 2007 /$ USA } & 4 & EX 33 & F 96 & $73.2 \pm 6.6$ & $29.8 \pm 4.2$ & Walking intensity Borg 11-16 \\
\hline & & RT 31 & M 35 & $74.1 \pm 6.2$ & $31.1 \pm 6.8$ & Thera-Bands, 13 exercises 2 sets of 12 reps \\
\hline & & Comb 32 & & $75.3 \pm 6.0$ & $29.0 \pm 5.3$ & Total time same as individual times \\
\hline & & Ctrl 35 & & $75.9 \pm 7.7$ & $29.4 \pm 4.6$ & Usual sedentary PA \\
\hline \multirow[t]{2}{*}{$\begin{array}{l}\text { Nishijima et al }{ }^{19} \\
\text { 2007/Japan }\end{array}$} & 6 & INT 281 & $\begin{array}{l}\text { F } 359 \\
\text { M } 171\end{array}$ & $67 \pm 6.7$ & $26.5 \pm 2.5$ & $\begin{array}{l}\text { Bicycle exercise } 2-4 \text { times/week, light RT } 60-90 \mathrm{~min} / \mathrm{session} \\
\text { at fitness club }\end{array}$ \\
\hline & & Ctrl 280 & & $66.9 \pm 6.9$ & $26.5 \pm 2.0$ & Usual care \\
\hline \multirow[t]{2}{*}{ Finucane et $a P^{0} 2010 / \mathrm{KK}$} & 3 & INT 50 & $\begin{array}{l}\text { F } 44 \\
\text { M } 56\end{array}$ & $71.4 \pm 4.2$ & $27.4 \pm 4.9$ & 3,1-h sessions/week @ 70\% W max $_{\max }$ \\
\hline & & Ctrl 50 & & $71.4 \pm 4.2$ & $26.9 \pm 3.6$ & Usual sedentary PA \\
\hline \multirow[t]{6}{*}{ Bocalini et $a f^{45} 2012 /$ Brazil } & 3 & AWC 9 & All $F$ & $67 \pm 9$ & $23 \pm 5$ & Circuit-based weight training \\
\hline & & AWT 18 & & $66 \pm 4$ & $22 \pm 1$ & 50 min 3 days/week \\
\hline & & OWC 10 & & $63 \pm 2$ & $26 \pm 1$ & \\
\hline & & OWT 14 & & $64 \pm 4$ & $27 \pm 1$ & \\
\hline & & OC 9 & & $62 \pm 1$ & $33 \pm 1$ & \\
\hline & & OT 9 & & $62 \pm 2$ & $34 \pm 1$ & \\
\hline Gudlaugsson et $a^{24}$ & 6 & Grp 1, 56 & M 25 & $80.8 \pm 4.7$ & $27.6 \pm 5.3$ & $20-45$ min walking, with 12 -exercise circuit 2 day/week \\
\hline 2013/Iceland & & Grp 2, 61 & $\begin{array}{l}\text { F } 31 \\
\text { M } 29 \\
\text { F } 32\end{array}$ & $78.3 \pm 4.1$ & $27.4 \pm 3.4$ & \\
\hline
\end{tabular}


Table 2 Quality measures of randomised controlled trials

\begin{tabular}{|c|c|c|c|c|}
\hline Study & $\begin{array}{l}\text { Generation of allocation } \\
\text { Number of randomised }\end{array}$ & Allocation concealment & Analysis basis & Attrition \\
\hline Stewart et $a f^{33}$ & $\begin{array}{l}\text { No information } \\
115\end{array}$ & Not reported & Number completed & $\begin{array}{l}\text { EX } 6 \\
\text { Ctrl } 5 \\
\text { All explained } \\
9.5 \%\end{array}$ \\
\hline Coker et $a^{P^{1}}$ & $\begin{array}{l}\text { No information } \\
21\end{array}$ & Not reported & $\begin{array}{l}\text { Original } 21 \\
\text { Did not specify ITT }\end{array}$ & $\begin{array}{l}\text { EX training } 1 \\
\mathrm{MI}(2), \mathrm{HI}(1) \text { did not } \mathrm{FU} \\
\text { for } \mathrm{VO}_{2} \mathrm{max} \\
19 \%\end{array}$ \\
\hline DiPietro et al ${ }^{17}$ & $\begin{array}{l}\text { No information } \\
25\end{array}$ & Not reported & $\begin{array}{l}\text { Original } 25 \\
\text { Did not specify ITT }\end{array}$ & Reported $90 \%$ retention overall \\
\hline Villareal et $a l^{18}$ & $\begin{array}{l}\text { Computer generated block } \\
\text { permutation, stratified for sex } \\
27\end{array}$ & Not reported & Intention to treat & $\begin{array}{l}\text { INT } 2 \text { non-compliant } \\
\text { Ctrl } 1 \text { no FU } \\
11 \%\end{array}$ \\
\hline Boardley et $a^{p^{2}}$ & $\begin{array}{l}\text { No information (published elsewhere) } \\
151\end{array}$ & Not reported & $\begin{array}{l}\text { Number who completed } 70 \% \\
\text { of exercise sessions }\end{array}$ & $13 \%$ \\
\hline Nishijima et $a l^{19}$ & $\begin{array}{l}\text { Lottery with block stratification for } \\
\text { fitness club, age and gender } \\
561\end{array}$ & Not reported & Intention to treat & $\begin{array}{l}\text { EX } 32 \\
\text { Ctrl } 28 \\
\text { All explained } \\
10.6 \%\end{array}$ \\
\hline Finucane et $a P^{0}$ & $\begin{array}{l}\text { No information } \\
100\end{array}$ & Not reported & Intention to treat & $\begin{array}{l}\text { EX } 2 \text { lost to FU } \\
\text { Ctrl } 2 \text { lost to FU } \\
4 \%\end{array}$ \\
\hline Bocalini et $a l^{45}$ & $\begin{array}{l}\text { No information } \\
78\end{array}$ & Not reported & $\begin{array}{l}\text { Number who completed } 90 \% \\
\text { of exercise sessions }\end{array}$ & $\begin{array}{l}2 \text { from AWT and } 7 \text { from OT } \\
\text { completed }<90 \% \text { of training } \\
\text { All explained } \\
11 \%\end{array}$ \\
\hline Gudlaugsson et $a^{R^{4}}$ & $\begin{array}{l}\text { No information } \\
117\end{array}$ & Not reported & Cross-over design, no loss to FU & $0 \%$ \\
\hline
\end{tabular}


Figure 2 The effect of exercise on body mass index (BMI).

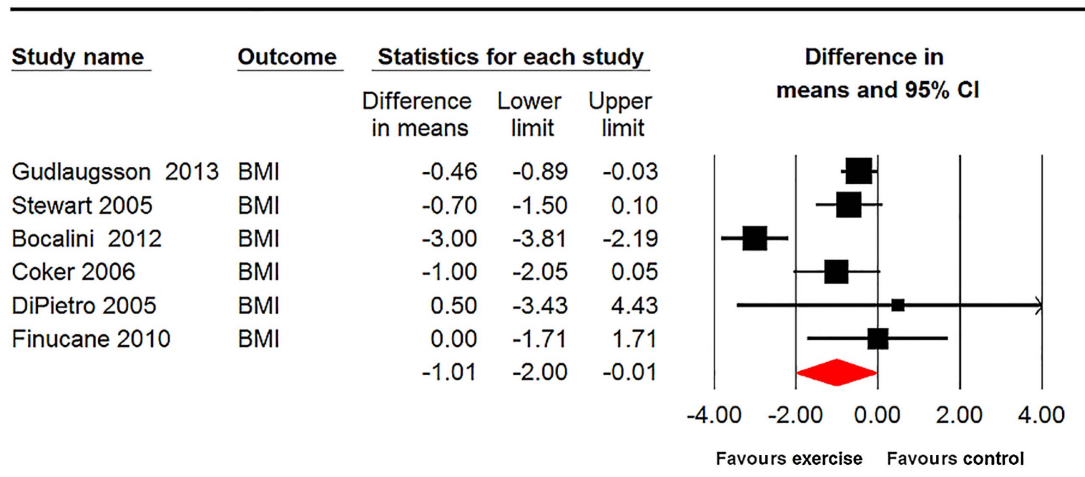

Meta Analysis

I squared $=84 \%$ interventions reviewed for this age category do seem to show a small but statistically significant reduction in BMI and WC, but not in LDL cholesterol.

Obesity in older people is a complex topic. BMIs of $\leq 24$ and $\geq 30 \mathrm{~kg} / \mathrm{m}^{2}$ are associated with increased mortality in older individuals. The Australian Longitudinal Study on Women's Health studied the optimal range for BMI in older women and found after a 5-year follow-up that the optimal weight associated with decreased mortality for women in their 70 s was a BMI of $25-27 \mathrm{~kg} / \mathrm{m}^{2}{ }^{25}$ Thus, being an overweight individual may be protective, while being obese may contribute to morbidity associated with overweight such as osteoarthritis, diabetes and impaired function. Older adults who are obese have been found to have poorer health than younger obese patients and non-obese older patients. ${ }^{26}$ Furthermore, the timing of weight gain may play a role. Several large epidemiological studies in participants over the age of 65 years have found that midlife weight gain is more strongly associated with decreased survival than weight gain in later life. ${ }^{27} 28$ Exercise effects may also be more pronounced in the middle-aged adult. A systematic review of the literature of women and men (mean age $47 \pm 6$ ) found aerobic exercise combined with a prudent diet to be highly effective for improving total cholesterol $(-15.5,95 \%$ CI -20.3 to -10.7$)$, LDL cholesterol
$(-9.2,95 \%$ CI -12.7 to -5.8$)$ and body weight $(-5.7$, $95 \%$ CI -7.4 to -4.1$){ }^{29}$

While this systematic review demonstrated improvements in BMI and WC, several other health benefits are expected in obese older adults such as the increase in lean muscle mass, prevention of osteoporosis and reductions in fall risk. ${ }^{30-32}$ Preventing or postponing disease onset in the older adult population is a crucial public health issue. Obesity can be predictive of a decline in physical function. ${ }^{5}{ }^{63-35}$ Combined with ageing, obesity can put the older persons at even greater risk for functional decline. ${ }^{36} 37$ One 14-year longitudinal trial found that overweight or obese women (mean age 74.3, $\mathrm{SD} \pm 4.3$ ) who remained active performed similar activities of daily living and walked at a similar gait speed as active and inactive normal weight women. ${ }^{38}$ Consistent with other studies, physical activity is considered an independent predictor of physical function in older individuals, even in the obese. ${ }^{39-41}$

Few older adults are meeting the American Heart Association and American College of Sports Medicine guidelines of $30 \mathrm{~min}$ of aerobic exercise five times a week for adults over age 65 years. ${ }^{1}$ In order to inform their public health guidelines, the Centers for Medicare and Medicaid performed a systematic review of studies that aimed to improve physical activity in the elderly.
Figure 3 The effect of exercise on waist circumference (WC).

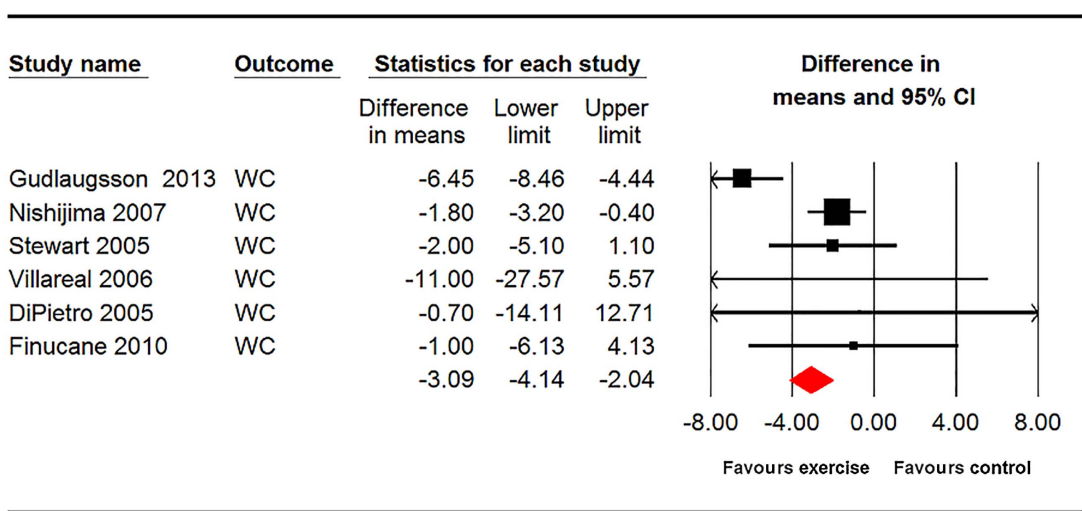


Figure 4 The effect of exercise on low-density lipoprotein (LDL) cholesterol.

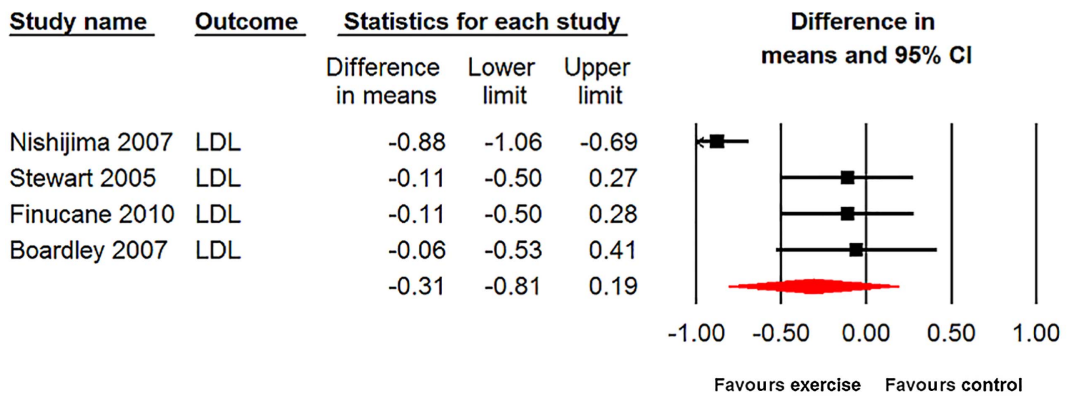

Meta Analysis

I squared $=88 \%$
The report concluded that motivating older adults to remain active was the most important public health objective. $^{42}$ Although the benefit of physical activity counselling in the primary care setting is inconclusive, a review carried out for the Guide to Community Preventive Services has identified effective programmes with behavioural, social and environmental components tailored to the individual's readiness for change. ${ }^{43} \mathrm{~A}$ cost-effectiveness analysis reported that 'individually adapted behaviour change' and 'social support' programmes are the least cost effective but produce the largest effect, adding $35-43 \%$ increases in recommended physical activity. ${ }^{44}$

The main limitations to this review include imprecision (small sample size and wide CIs) and heterogeneity (varying interventions and study settings). Therefore, despite the fact that the overall methodological quality of the trials was fair, the quality of the evidence (ie, confidence in estimates) is limited. The length of follow-up was not sufficiently long, although this is typical of trials of lifestyle modifications in which maintaining long-term adherence is challenging. Furthermore, results may not be fully generalisable since most participants were Caucasian and trials excluded participants at higher risk for exercise adverse effects. Publication bias could not be adequately assessed due to the small number of included studies and due to heterogeneity, but it is possible in a field that mainly consists of small trials. Loss to follow-up could also have biased the observed estimates. Nonetheless, this systematic review has several strengths, including comprehensive search of multiple databases and selecting studies by two independent reviewers. We believe the evidence summarised in this report is important and relevant for the development of lifestyle modification programmes targeting older adults, an increasing proportion of the population.

\section{CONCLUSIONS}

Exercise in obese older individuals improves anthropometric measures such as BMI and WC. Despite the limitations in the current evidence, lifestyle modification programmes targeting older adults are justified.

Acknowledgements The authors appreciate the teachings of Robert Kane, MD; Tatyana Shamliyan, MD, MS and Mary Butler, PhD who were the systematic review course instructors at the University of Minnesota, Minneapolis, Minnesota, USA.

Contributors CLK created the study design, did the initial literature search and drafted the manuscript including the statistical analysis. MWS was the second reviewer and edited the manuscript. PJA contributed to data collection and critically revised the manuscript. MHM assisted with the study design and critically revised the manuscript. All authors read and approved the final manuscript.

Funding This research received no specific grant from any funding agency in the public, commercial or not-for-profit sectors.

Competing interests None.

Provenance and peer review Not commissioned; externally peer reviewed.

Data sharing statement No additional data are available.

Open Access This is an Open Access article distributed in accordance with the Creative Commons Attribution Non Commercial (CC BY-NC 4.0) license, which permits others to distribute, remix, adapt, build upon this work noncommercially, and license their derivative works on different terms, provided the original work is properly cited and the use is non-commercial. See: http:// creativecommons.org/licenses/by-nc/4.0/

\section{REFERENCES}

1. US Department of Health and Human Services OoDPaHP. Healthy people 2010. With understanding and improving health and objectives for improving health. 2nd edn. Washington, DC: Government Printing Office, 2000.

2. Janssen I, Mark AE. Elevated body mass index and mortality risk in the elderly. Obes Rev 2007:8:41-59.

3. Lakka HM, Lakka TA, Tuomilehto J, et al. Abdominal obesity is associated with increased risk of acute coronary events in men. Eur Heart J 2002;23:706-13.

4. He W, Sengupta M, Velkoff V, et al. 65+ In the United States, 2005. Bureau USC. Washington, DC: US Government Printing Office, 2005.

5. Harris AM, Lanningham-Foster LM, McCrady SK, et al. Nonexercise movement in elderly compared with young people. Am J Physiol Endocrinol Metab 2007;292:E1207-12.

6. Villareal DT, Apovian CM, Kushner RF, et al. Obesity in older adults: technical review and position statement of the American Society for Nutrition and NAASO, The Obesity Society. Obes Res 2005;13:1849-63.

7. Baumgartner RN, Waters DL, Gallagher D, et al. Predictors of skeletal muscle mass in elderly men and women. Mech Ageing Dev 1999;107:123-36. 
8. Prevention CfDCa. Behavioral Risk Factor Surveillance System, National Center for Chronic Disease Prevention and Health Promotion.

9. Beydoun MA, Beydoun HA, Wang Y. Obesity and central obesity as risk factors for incident dementia and its subtypes: a systematic review and meta-analysis. Obes Rev 2008;9:204-18.

10. Latham NK, Bennett DA, Stretton CM, et al. Systematic review of progressive resistance strength training in older adults. $J$ Gerontol $A$ Biol Sci Med Sci 2004:59:48-61.

11. McTigue KM, Hess R, Ziouras J. Obesity in older adults: a systematic review of the evidence for diagnosis and treatment. Obesity (Silver Spring) 2006;14:1485-97.

12. Gostic CL. The crucial role of exercise and physical activity in weight management and functional improvement for seniors. Clin Geriatr Med 2005;21:747-56, vii.

13. Higgins JP, Altman DG, Gotzsche PC, et al. The Cochrane Collaboration's tool for assessing risk of bias in randomised trials. BMJ 2011;343:d5928.

14. DerSimonian R, Laird N. Meta-analysis in clinical trials. Control Clin Trials 1986;7:177-88.

15. Higgins JP, Thompson SG, Deeks JJ, et al. Measuring inconsistency in meta-analyses. BMJ 2003;327:557-60.

16. Lau J, loannidis JP, Terrin N, et al. The case of the misleading funnel plot. BMJ 2006;333:597-600.

17. DiPietro L, Dziura J, Yeckel CW, et al. Exercise and improved insulin sensitivity in older women: evidence of the enduring benefits of higher intensity training. J Appl Physiol (1985) 2006; 100:142-9.

18. Villareal DT, Miller BV III, Banks M, et al. Effect of lifestyle intervention on metabolic coronary heart disease risk factors in obese older adults. Am J Clin Nutr 2006:84:1317-23.

19. Nishijima H, Satake K, Igarashi K, et al. Effects of exercise in overweight Japanese with multiple cardiovascular risk factors. Med Sci Sports Exerc 2007;39:926-33.

20. Finucane FM, Sharp SJ, Purslow LR, et al. The effects of aerobic exercise on metabolic risk, insulin sensitivity and intrahepatic lipid in healthy older people from the Hertfordshire Cohort Study: a randomised controlled trial. Diabetologia 2010;53:624-31.

21. Coker RH, Hays NP, Williams RH, et al. Exercise-induced changes in insulin action and glycogen metabolism in elderly adults. Med Sci Sports Exerc 2006;38:433-8.

22. Boardley D, Fahlman M, Topp R, et al. The impact of exercise training on blood lipids in older adults. Am J Geriatr Cardiol 2007:16:30-5.

23. Stewart KJ, Bacher AC, Turner K, et al. Exercise and risk factors associated with metabolic syndrome in older adults. Am J Prev Med 2005;28:9-18.

24. Gudlaugsson J, Aspelund T, Gudnason V, et al. [The effects of 6 months' multimodal training on functional performance, strength, endurance, and body mass index of older individuals. Are the benefits of training similar among women and men?]. Laeknabladid 2013;99:331-7.

25. van Uffelen JG, Berecki-Gisolf J, Brown WJ, et al. What is a healthy body mass index for women in their seventies? Results from the Australian longitudinal study on women's health. J Gerontol A Biol Sci Med Sci 2010;65:847-53.

26. Jee SH, Sull JW, Park J, et al. Body-mass index and mortality in Korean men and women. N Engl J Med 2006;355:779-87.
27. Harris TB, Launer LJ, Madans J, et al. Cohort study of effect of being overweight and change in weight on risk of coronary heart disease in old age. BMJ 1997;314:1791-4.

28. Losonczy KG, Harris TB, Cornoni-Huntley J, et al. Does weight loss from middle age to old age explain the inverse weight mortality relation in old age? Am J Epidemiol 1995;141:312-21.

29. Kelley GA, Kelley KS, Roberts S, et al. Efficacy of aerobic exercise and a prudent diet for improving selected lipids and lipoproteins in adults: a meta-analysis of randomized controlled trials. BMC Med 2011;9:74

30. Frimel TN, Sinacore DR, Villareal DT. Exercise attenuates the weight-loss-induced reduction in muscle mass in frail obese older adults. Med Sci Sports Exerc 2008;40:1213-19.

31. Kelley GA, Kelley KS, Tran ZV. Exercise and bone mineral density in men: a meta-analysis. J Appl Physiol (1985) 2000;88:1730-6.

32. Wolff I, van Croonenborg JJ, Kemper HC, et al. The effect of exercise training programs on bone mass: a meta-analysis of published controlled trials in pre- and postmenopausal women. Osteoporos Int 1999;9:1-12.

33. Bales $\mathrm{CW}$, Buhr $\mathrm{G}$. Is obesity bad for older persons? A systematic review of the pros and cons of weight reduction in later life. J Am Med Dir Assoc 2008;9:302-12.

34. Jensen GL, Hsiao PY. Systematic review and meta-analysis: systematic review finds modest weight loss at 1 year but a lack of high-quality evidence to support the efficacy of programmes encouraging weight loss in older people. Evid Based Med 2010;15:41-2.

35. Launer LJ, Harris T, Rumpel C, et al. Body mass index, weight change, and risk of mobility disability in middle-aged and older women. The epidemiologic follow-up study of NHANES I. JAMA 1994;271:1093-8.

36. Grabowski DC, Ellis JE. High body mass index does not predict mortality in older people: analysis of the Longitudinal Study of Aging. J Am Geriatr Soc 2001;49:968-79.

37. Guralnik JM, Simonsick EM. Physical disability in older Americans. $J$ Gerontol 1993;48 Spec No:3-10.

38. Brach JS, VanSwearingen JM, FitzGerald SJ, et al. The relationship among physical activity, obesity, and physical function in community-dwelling older women. Prev Med 2004;39:74-80.

39. LaCroix AZ, Guralnik JM, Berkman LF, et al. Maintaining mobility in late life. II. Smoking, alcohol consumption, physical activity, and body mass index. Am J Epidemiol 1993;137:858-69.

40. Lee CD, Blair SN, Jackson AS. Cardiorespiratory fitness, body composition, and all-cause and cardiovascular disease mortality in men. Am J Clin Nutr 1999;69:373-80.

41. Wei M, Kampert JB, Barlow CE, et al. Relationship between low cardiorespiratory fitness and mortality in normal-weight, overweight, and obese men. JAMA 1999;282:1547-53.

42. Snowden M, Steinman L, Mochan K, et al. Effect of exercise on cognitive performance in community-dwelling older adults: review of intervention trials and recommendations for public health practice and research. J Am Geriatr Soc 2011;59:704-16.

43. Shekelle P, Manglione M, Mojica W, et al. Exercise programs for older adults. Santa Monica, CA: RAND Corporation, 2003.

44. Wu S, Cohen D, Shi $\mathrm{Y}$, et al. Economic analysis of physical activity interventions. Am J Prev Med 2011;40:149-58.

45. Bocalini DS, Lima LS, de Andrade S, et al. Effects of circuit-based exercise programs on the body composition of elderly obese women. Clin Interv Aging 2012;7:551-6. 